\title{
Project ALERT reduces initiation of cigarette and marijuana use in 12-14 year olds
}

Ellickson PL, McCaffrey DF, Ghosh-Dastidar B, et al. New inroads in preventing adolescent drug use: results from a large-scale trial of project ALERT in middle schools. Am J Public Health 2003;93:1830-6.

Does the revised Project ALERT reduce substance misuse among middle school students?

\section{METHODS}

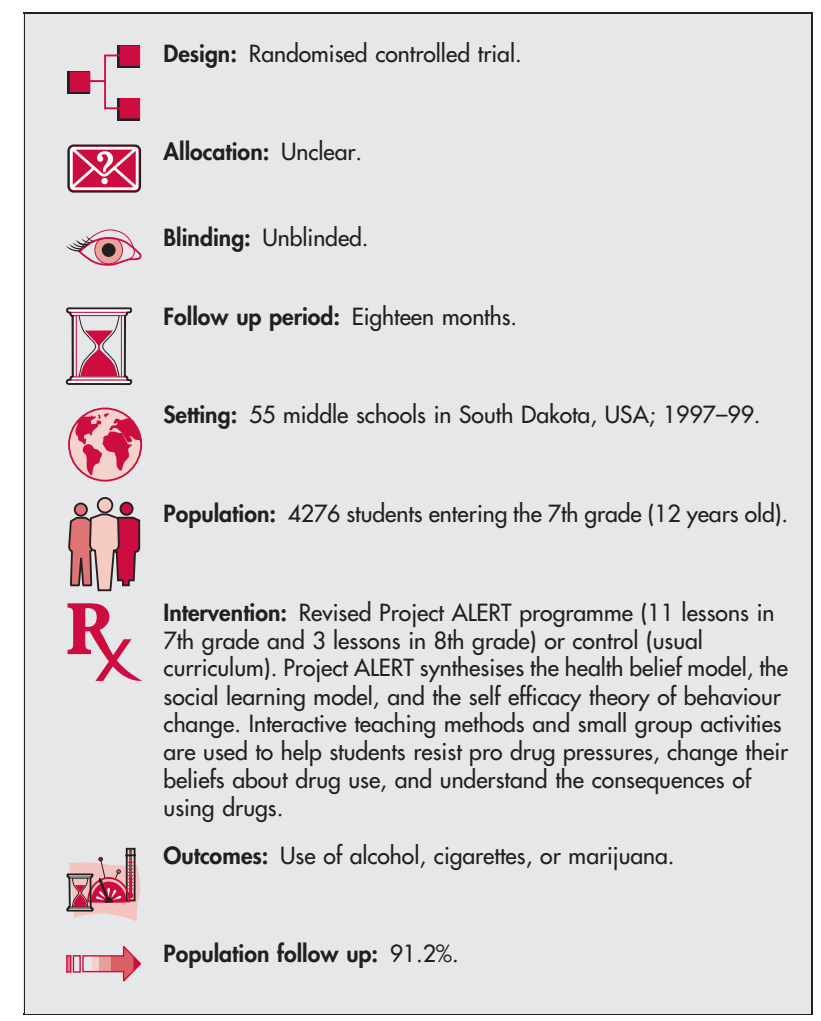

\section{MAIN RESULTS}

Project ALERT significantly reduced the proportion of new cigarette and new marijuana users but not new alcohol users, compared with control at 18 months (cigarettes: $25.5 \%$ with ALERT $v 31.6 \%$ with control; RRR 19\%; p<0.01; marijuana: 13\% with ALERT $v$ 17\% with control; RRR 24\%; p <0.01; alcohol: results not shown). Project ALERT significantly reduced the proportion of students who had used cigarettes, but did not significantly reduce the proportion who had used marijuana or alcohol in the month prior to 18 month follow up (cigarettes: RRR 23\%, p <0.01; marijuana: RRR 15\%, not significant; alcohol: results not shown).

For correspondence: Dr P Ellickson, RAND, Santa Monica, California, USA; phyllis_ellickson@rand.org

Sources of funding: National Institute on Drug Abuse, The BEST Foundation for a Drug-Free Tomorrow, and The Conrad N Hilton Foundation.

\section{CONCLUSIONS}

Project ALERT is effective for reducing current smoking and initiation of smoking, but not drinking, in middle school students.

\section{Commentary}

This paper builds on the current "push" to get evidence based programming out into the field and the "pull" to get disseminated programming more scientifically rigorous. Project ALERT is one of the two most widely disseminated evidence based drug abuse prevention programmes right now (along with Life Skills Training) due to aggressive marketing and monetary subsidisation from the Hilton Foundation. However, its effects were known to be weak on cigarette smoking and alcohol use, and its overall effects disappeared over time. ${ }^{12}$ This school based programme originally offered eight sessions in 7 th grade $(12$ year olds) and three booster sessions in 8th grade (13 year olds). Three new sessions were added for the current trial. These included information on smoking cessation (including a video of teen quitters), personal susceptibility to negative consequences of and alternatives to alcohol use, and parental involvement activities (discussions of social influences and drug use consequences). In addition, the current trial was implanted in South Dakota middle schools, a new location (Midwestern US), and was evaluated through an experimental design, revealing effects on ever use, past month use, and weekly use of cigarettes, ever use of marijuana, and problematic drinking (though not trial or current drinking) at an 18 month follow up. Generally, these effects held across baseline level of drug use ("baseline risk status").

This study provides a revised and stronger version of Project ALERT, which can be inserted into its dissemination efforts. Of course, the current programme still needs to be evaluated over the transition to high school (14 year olds and above) to see if programme effects are maintained. However, among other findings this programme, along with one other with senior high school youth (14-18 year olds; Project TND ${ }^{3}$ ), shows that combining cessation programming along with prevention programming is likely to enhance the effectiveness of drug education among the young. Although a content and process analysis of all evidence based drug abuse prevention programming might more fully elucidate the mediation of these programmes' effects, this paper shows that the drive to institutionalise evidence based programming can be met with programme improvements along the way.

$$
\begin{array}{r}
\text { Steve Sussman, PhD FAAHB } \\
\text { Departments of Preventive Medicine and Psychology, University of } \\
\text { Southern California, USA }
\end{array}
$$

1 Ellickson PL, Bell RM, McGuigan K. Preventing adolescent drug use: longterm results of a junior high program. Am J Public Health 1993;83:856-61. 2 Skara S, Sussman S. A review of 25 long-term adolescent tobacco and other drug use prevention program evaluations. Prev Med 2003;37:45174.

3 Sussman S, Sun P, McCuller WJ, et al. Project Towards No Drug Abuse: two-year outcomes of a trial that compares health educator delivery to selfinstruction. Prev Med 2003;37:155-62. 